\title{
Thermospheric density and wind retrieval from Swarm observations
}

\author{
Pieter Visser, Eelco Doornbos, Jose van den IJssel, and João Teixeira da Encarnação \\ Delft University of Technology, Faculty of Aerospace Engineering, Kluyverweg 1, 2629 HS, Delft, The Netherlands
}

(Received November 27, 2012; Revised August 20, 2013; Accepted August 21, 2013; Online published November 22, 2013)

\begin{abstract}
The three-satellite ESA Swarm mission aims at mapping the Earth's global geomagnetic field at unprecedented spatial and temporal resolution and precision. Swarm also aims at observing thermospheric density and possibly horizontal winds. Precise orbit determination (POD) and Thermospheric Density and Wind (TDW) chains form part of the Swarm Constellation and Application Facility (SCARF), which will provide the so-called Level 2 products. The POD and TDW chains generate the orbit, accelerometer calibration, and thermospheric density and wind Level 2 products. The POD and TDW chains have been tested with data from the CHAMP and GRACE missions, indicating that a 3D orbit precision of about $10 \mathrm{~cm}$ can be reached. In addition, POD allows to determine daily accelerometer bias and scale factor values with a precision of around $10-15 \mathrm{~nm} / \mathrm{s}^{2}$ and $0.01-0.02$, respectively, for the flight direction. With these accelerometer calibration parameter values, derived thermospheric density is consistent at the $9-11 \%$ level (standard deviation) with values predicted by models (taking into account that model values are 20-30\% higher). The retrieval of crosswinds forms part of the processing chain, but will be challenging. The Swarm observations will be used for further developing and improving density and wind retrieval algorithms.
\end{abstract}

Key words: Swarm, precise orbit determination, thermospheric density, thermospheric winds.

\section{Introduction}

The European Space Agency (ESA) Swarm Earth Explorer mission aims at the best global survey ever of the Earth's magnetic field and its variations (ESA, 2004). The planned lift-off is in Autumn 2013 (status June 2013) by a Rockot launcher from Plesetsk, Russia, and the nominally foreseen lifetime is four years. The primary objective of the mission is to map the Earth's global magnetic field and its temporal variations with unprecedented accuracy and precision. To this aim, the Swarm satellites are amongst other instruments equipped with scalar and vector magnetometers (Friis-Christensen et al., 2008). Moreover, each Swarm satellite carries three star trackers allowing a precise attitude reconstruction for all latitudes and local times. In addition, the satellites carry high-precision, dual-frequency Global Positioning System (GPS) receivers for precise orbit determination and accelerometers for observing non-gravitational accelerations. Furthermore, laser retro-reflector arrays allow Satellite Laser Ranging (SLR) by ground stations, which offers the opportunity to validate the orbits computed from the GPS Satellite-to-Satellite Tracking (SST) observations. As a secondary objective, the instrument suite on board of the Swarm satellites allows the derivation of the neutral density of the upper atmosphere, i.e. the thermospheric density, and, if conditions are favorable, also thermospheric winds. This provides supporting information for studying the dynamics of the upper atmosphere, which results from a complex interaction between

Copyright (C) The Society of Geomagnetism and Earth, Planetary and Space Sciences (SGEPSS); The Seismological Society of Japan; The Volcanological Society of Japan; The Geodetic Society of Japan; The Japanese Society for Planetary Sciences; TERRAPUB.

doi:10.5047/eps.2013.08.003 the charged particles and the neutrals in the ambient magnetic field.

Using accelerometers for deriving neutral thermospheric density and wind values was already demonstrated successfully many decades ago by Marcos et al. (1977) and Marcos and Forbes (1985). The very precise accelerometers on board of CHAMP and GRACE (Reigber et al., 1999; Tapley and Reigber, 1999) significantly enhanced and extended this use. The accelerometers have not only made it possible to observe thermospheric density and winds at improved precision at unprecedented global spatial and temporal resolution, but have also resulted in a better understanding of their behavior and evolution (Bruinsma et al., 2004, 2006; Lühr et al., 2004, 2007; Forbes et al., 2005; Liu and Lühr, 2005; Liu et al., 2005, 2006; Doornbos et al., 2009). As a spin-off, the accelerometer observations provide insight into modeling satellite drag coefficients as well and support the enhancement of underlying theories for upper atmospheric models (Bowman et al., 2008). It is claimed that the Swarm accelerometers will have a resolution comparable to the CHAMP STAR accelerometer of better than 3 $\mathrm{nm} / \mathrm{s}^{2}$ and a noise level below $10 \mathrm{~nm} / \mathrm{s}^{2}$ (Zaglauer, 2009). The Swarm accelerometers are claimed to have the same performance for all three axes, opposed to the CHAMP and GRACE accelerometers, which have two very sensitive axes and one relatively less sensitive axis. The Attitude and Orbit Control System (AOCS) of the Swarm satellites will maintain an Earth oriented satellite attitude within a control band of $5^{\circ}$ around roll, pitch and yaw, compared to $2^{\circ}$ for e.g. CHAMP (Helleputte and Visser, 2009). It is anticipated that for Swarm the amount of accelerometer data affected by the propulsion system will be limited (see e.g. 
also figures 8-4 and 8-5 in the Technical and Programmatic Annex of ESA (2004)).

The Swarm constellation will consist of three satellites in near-polar Low Earth Orbit (LEO), with one pair flying side-by-side at an initial altitude of about $450 \mathrm{~km}$, and a single satellite flying at about $530 \mathrm{~km}$ altitude. This constellation provides unique sampling in both (local solar) time and space (ESA, 2004). Therefore, the derivations of thermospheric density and wind values from the relevant Swarm observations form part of the activities by the Swarm Satellite Constellation Application and Research Facility-SCARF (Olsen et al., 2011). The SCARF will be responsible for the Swarm Level 2 Processing System (L2PS) under contract of ESA. The L2PS is responsible for generating advanced so-called Level 2 data products.

The focus of this paper is on the L2PS part that produces the thermospheric density and wind products. The associated chain is the responsibility of - and is implemented at - the Faculty of Aerospace Engineering, Delft University of Technology (TU Delft). After briefly introducing the concept of thermospheric density and wind retrieval (Section 2), the design and implementation of the TU Delft processing system is outlined (Section 3 ). This system has been tested using real data from the CHAMP and GRACE missions (Section 4). Finally, a summary is provided and conclusions are drawn (Section 5).

\section{Thermospheric Density and Winds}

As a starting point, it has to be recognized that the nongravitational acceleration as observed by an accelerometer on board of a LEO satellite is composed of several contributions. The observed acceleration can be written as:

$$
\mathbf{s}\left(\mathbf{a}_{\mathrm{obs}}+\mathbf{b}\right)=\mathbf{a}_{\mathrm{aero}}+\mathbf{a}_{\mathrm{srp}}+\mathbf{a}_{\mathrm{alb}}+\mathbf{a}_{\mathrm{IR}}+\mathbf{a}_{\mathrm{rem}}
$$

where $\mathbf{a}_{\mathrm{obs}}$ and $\mathbf{a}_{\text {aero }}$ represent respectively the observed and aerodynamic acceleration vector. Please note that it is assumed that the accelerometer takes its observations in three perpendicular directions. The terms $\mathbf{a}_{\text {srp }}, \mathbf{a}_{\mathrm{alb}}$ and $\mathbf{a}_{\mathrm{IR}}$ denote the accelerations caused by solar radiation pressure, Earth's albedo and Earth's infrared radiation, respectively. Finally, $\mathbf{a}_{\text {rem }}$ represents all remaining contributions, which are assumed to be small or negligible, such as observation noise, correction errors and other accelerations. It has to be noted that the original accelerometer observations $\mathbf{a}_{\text {obs }}$ typically have to be corrected for scale factors and biases, represented by respectively the vectors $\mathbf{s}$ and $\mathbf{b}$ (Visser and van den IJssel, 2003; Bruinsma et al., 2004; Helleputte and Visser, 2009). It is assumed that the location of the accelerometer coincides with the center-of-mass of the satellite. Equation (1) shows that the (calibrated) accelerometer observation needs to be reduced by the accelerations due to solar radiation pressure, albedo and infrared radiation to arrive at the actual aerodynamic acceleration. To this aim, precise models have been implemented (Doornbos et al., 2010). As for the derivation of thermospheric density and wind from the aerodynamic acceleration $\mathbf{a}_{\text {aero }}$, these models require detailed information about the satellite attitude and geometry (see below).

The aerodynamic acceleration is caused by the combined effect of atmospheric drag and wind. It can be written as:

$$
\mathbf{a}_{\mathrm{aero}}=\mathbf{C}_{a} \frac{A_{\mathrm{ref}}}{m} \frac{1}{2} \rho v_{r}^{2}
$$

where $\mathbf{C}_{a}$ represents the force coefficient vector, and $m$ the mass of the satellite. $A_{\text {ref }}$ typically denotes the crosssectional area, i.e. the projection of the satellite geometry perpendicular to $\mathbf{v}_{r}$, which is the velocity relative to the Earth's atmosphere, with $v_{r}$ being its norm. The mass density is represented by $\rho$. If the aerodynamic force components perpendicular to the velocity direction (lift and sideways forces) are omitted, the aerodynamic acceleration reduces to just a drag acceleration $a_{\text {drag }}$, which is (by definition) in the direction of the velocity of the atmospheric particles relative to the spacecraft. Equation (2) then reduces to:

$$
\mathbf{a}_{\mathrm{drag}}=C_{D} \frac{A_{\mathrm{ref}}}{m} \frac{1}{2} \rho v_{r}^{2} \hat{\mathbf{v}}_{\mathbf{r}}
$$

where $C_{D}$ is the scalar drag coefficient and $\hat{\mathbf{v}}_{\mathbf{r}}$ the unit vector in the direction of the velocity $\mathbf{v}_{r}$. The velocity $\mathbf{v}_{r}$ can be written as:

$$
\mathbf{v}_{r}=\mathbf{v}_{o}+\mathbf{v}_{c}+\mathbf{v}_{\mathbf{w}}
$$

where $\mathbf{v}_{o}, \mathbf{v}_{c}$ and $\mathbf{v}_{\mathbf{w}}$ represent the inertial velocity of the satellite, the velocity caused by the Earth's corotating atmosphere, and the wind velocity, respectively. The aerodynamic acceleration thus indeed depends not only on the atmospheric density, but also on the prevailing winds. Doornbos et al. (2010) have developed an iterative method for deriving the mass density $\rho$ and wind $v_{w}$.

When considering Eqs. (2) and (3), it becomes clear that information about the satellite and its orientation is required. Information about the satellite attitude needs to be provided as well in combination with a detailed model of its geometry in order to compute the cross-sectional area $A_{\text {ref. }}$ Since the Swarm satellites are equipped with three star trackers, this attitude can be observed very precisely. Accurate satellite geometry models consisting of precisely positioned and shaped panels can be created with specialized software, such as ANGARA (Fritsche et al., 1998), based on CAD drawings. The computation of $\mathbf{C}_{a}$ or $C_{D}$ from the geometry model is rather convoluted (Sentman, 1961; Cook, 1965; Moe and Moe, 1996; Moe et al., 1998) and is in fact still a matter of much debate (Moe and Moe, 2006; Bowman et al., 2008; Doornbos et al., 2010; Doornbos, 2011). Currently, the aerodynamic coefficients are based on non-hyperthermal free molecular flow calculations on single-sided flat plates, with a gas-surface interaction based on diffuse reflection, and an initial value for the energy accommodation coefficient of 0.93 (Sentman, 1961; Moe and Moe, 2005). For Swarm, an attempt to obtain a value for the energy accommodation coefficient from the acceleration data will be made during the commissioning phase.

The solar radiation pressure model takes into account the variations due to changes in the Sun-satellite distance, and a conical shadow model making use of spherical representations of the Earth and Moon. The shadow model includes a simple approximation for absorption and refraction of Sunlight in the Earth's lower atmosphere. Earth albedo and infrared radiation pressure are based on monthly averaged 2.5 
deg by 2.5 deg grids of ERBE data, made from the ERBS, NOAA-9 and NOAA-10 satellites over a few years in the mid-1980s. For the computation of radiation forces, accurate models for the satellite's geometry and its optical properties are required as well (Doornbos, 2011).

Table 1 provides an overview of the supporting satellite information that is required. Most of this information can be obtained prelaunch by accurately measuring and balancing all the satellite subsystems. Part of the information is to be regularly updated, such as changing mass of the satellite due to fuel consumption. This information is crucial to fully exploit the information content of the observations that Swarm will provide. Since Swarm consists of identical satellites flying at different altitudes and orbital planes with a slowly evolving local solar time of the ascending node, unique data will be collected that will enhance methods and theories for computing or deriving the drag coefficients.

\section{Processing Facility}

A processing facility has been developed by the section Astrodynamics and Space Missions of the Faculty of Aerospace Engineering at the TU Delft that aims at producing the best possible geolocated time series of thermospheric density and wind at the Swarm satellite locations. This TU Delft processing facility is sub-divided into two chains, each consisting of separate modules. Each of these modules can be tuned in accordance with the assumed or shown quality of the Swarm observations of input data. The two chains are referred to as Precise Orbit Determination (POD) and Thermospheric Density and Wind (TDW) retrieval (Fig. 1). The chains make use of both observational data and information coming from the so-called ESA Payload Data Ground Segment (PDGS) and several external providers, such as the International GNSS Service (IGS), International Laser Ranging Service (ILRS), International Earth Rotation Service (IERS), etc. (Pearlman et al., 2002; McCarthy and Petit, 2004; Dow et al., 2005). Although the focus of this paper is on the TDW retrieval, the POD chain involves necessary preparatory steps and interim products. The POD chain also supports the primary objective of the Swarm mission by providing the information for precise geolocating of the magnetic field observations. Furthermore, its products will be used for gravity field retrieval, which can be considered a spin-off application of the Swarm mission, or a possible tertiary objective (Gerlach and Visser, 2006).

As indicated above, the POD chain provides the information for precise geolocation of Swarm observations, including the measurements provided by the accelerometers. In addition, the POD chain takes care of the calibration of the accelerometer observations along the $X$ axis, which predominantly coincides with the flight direction of the Swarm orbital motion. The associated bias and scale factor values (Eq. (1)) are used as starting values in the TDW chain for a (partly iterative) procedure to obtain calibration parameters for the $Y$ and $Z$ axis as well, which more or less coincide with the orbital cross-track and radial direction, respectively. The TDW chain also takes care of the reduction or correction of the calibrated observations to derive the aerodynamic accelerations (Eq. (1)) and the thermospheric density and wind (Doornbos et al., 2010; Doornbos, 2011). The POD and TDW chains are outlined in more detail in the next Sections.

\subsection{Precise orbit determination}

As mentioned before, POD is required for geolocating the observations taken by the scientific instruments on board of the Swarm satellites. The on-board GPS receivers will provide tracking observations. These observations have to be augmented by auxiliary and internal data that are collected and provided routinely by existing networks of ground stations and services such as the IGS, ILRS and IERS. Moreover, the POD chain involves the estimation of accelerometer calibration parameters and a number of spinoff products. The overall processing and product flow for the POD processor is shown in Fig. 2.

The POD chain involves four tasks:

(i) Data pre-processing;

(ii) Orbit setup;

(iii) Orbit computation;

(iv) Quality assessment.

(i) The data pre-processing consists of the collection of all required Swarm observational data, including observations provided by the GPS receivers, star trackers and accelerometers. In addition, use is made of data products provided by the IGS, ILRS and IERS. The data preprocessing involves quality checking of the observations, such as elimination of spurious observations, reformatting, etc. Although accelerometer observations are not required for computing time series of satellite positions and velocities, for Swarm they will be used in a separate orbit determination runs for estimating the calibration parameters.

(ii) The orbit setup involves the definition of the dynamic models to be used, the parameters to be estimated, definition of the arc length, etc. As a preparatory step, necessary data sets and models will be collected from external providers, such as JPL planetary ephemeris (e.g. for modeling $3^{\text {rd }}$ body perturbations) and gravity field and tide models.

(iii) After defining the setup, the actual orbit parameter estimation will be done. For Swarm, a reduced-dynamic orbit determination approach will be adopted using the GHOST software for providing high-precision time series of positions and velocities (Montenbruck et al., 2005). The GHOST software is developed under auspices of the DLR German Space Operations Centre together with the TU Delft. The kinematic orbit solution will also be provided as an additional product. This kinematic orbit solution can be considered as a condensed set of the original GPS SST observations and it will serve as pseudo observations for a dynamic orbit determination that is done with the purpose of providing accelerometer calibration parameters (needed by the TDW chain, Subsection 3.2). In this dynamic orbit determination, the non-gravitational accelerations are represented by the accelerometer observations. Typically, use is made of daily arcs where the estimated parameters are the begin position and velocity of the satellite, and one bias and scale factor for each accelerometer axis (Visser and van den IJssel, 2003). Especially for the flight direction, very precise estimates can be obtained for accelerometer bias and scale factor (Helleputte and Visser, 2009). In fact, only the $X$-axis calibration parameters are retained for fur- 
Table 1. Required satellite specific information for tracking and accelerometer data processing.

\begin{tabular}{|c|c|}
\hline Item & Description \\
\hline $\begin{array}{l}\text { Definition of reference } \\
\text { frame(s) }\end{array}$ & $\begin{array}{l}\text { Written description and drawing indicating the location of the origin and directions of the principal axes in } \\
\text { which satellite geometry-related information is specified. }\end{array}$ \\
\hline $\begin{array}{l}\text { Geometry of the satellite ex- } \\
\text { ternal surfaces }\end{array}$ & $\begin{array}{l}\text { Dimensions, locations and orientations of the satellite outer panels, to be used for non-gravitational force } \\
\text { model calculations. To be provided in the form of dimensioned drawings, and a table containing the area } \\
\text { and normal vector for each major satellite panel. }\end{array}$ \\
\hline $\begin{array}{l}\text { Materials and optical proper- } \\
\text { ties of the satellite external } \\
\text { surfaces }\end{array}$ & $\begin{array}{l}\text { For each material used on the exterior of the satellite, the fractions of absorbed light, diffusely reflected } \\
\text { light and specularly reflected light need to be specified in a table and/or drawing. Characteristic values } \\
\text { for visible and infrared wavelengths are required for solar and earth radiation pressure modeling, resulting } \\
\text { in two times three coefficients per material. For each of these materials, drawings should make clear on } \\
\text { which sections of the spacecraft exterior this surface material is used. }\end{array}$ \\
\hline $\begin{array}{l}\text { Locations of center of mass, } \\
\text { instruments and antennae ref- } \\
\text { erence points }\end{array}$ & $\begin{array}{l}\text { Table containing the coordinates in the satellite reference frame of the location of the accelerometer } \\
\text { instrument and tracking instrumentation reference points, and of the initial location of the center of mass, } \\
\text { and the possible range of the variation of the center of mass due to fuel consumption. }\end{array}$ \\
\hline Thruster activation data & $\begin{array}{l}\text { Information on the activation of thrusters consisting of identification of activated thruster(s) (location and } \\
\text { direction in } \mathrm{S} / \mathrm{C} \text { frame), thrust duration, thrust magnitude. }\end{array}$ \\
\hline
\end{tabular}

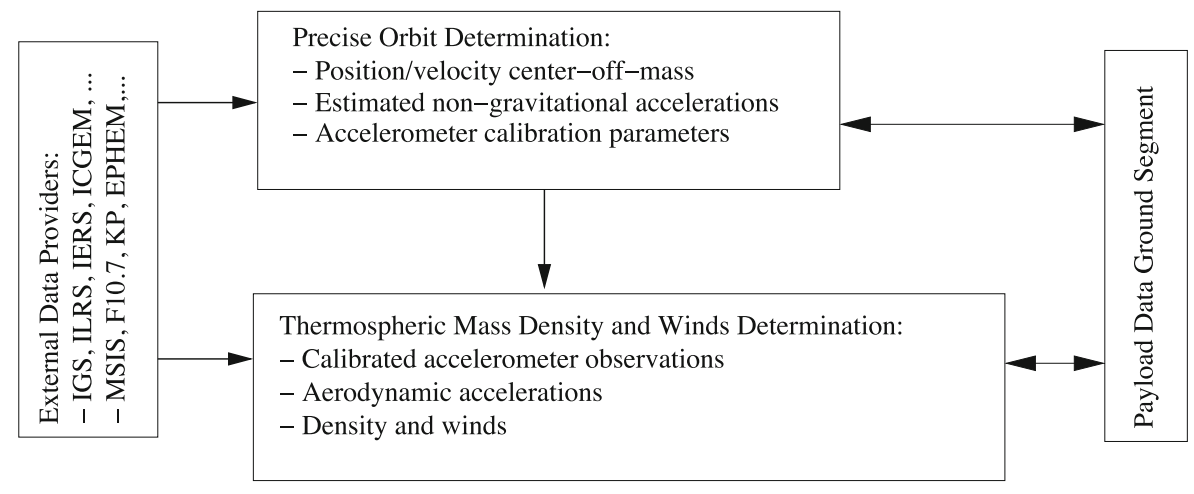

Fig. 1. TU-Delft processing facility.

ther use (Subsection 3.2). This dynamic orbit determination is done with the GEODYN parameter estimation software, kindly provided by the NASA Goddard Space Flight Center (Pavlis et al., 2006). A highly reduced-dynamic orbit determination will be done as well for obtaining time series of non-gravitational accelerations (van den IJssel and Visser, 2004a, b). These time series are used for validation of the accelerometer observations and also serve as a (partial) backup for the accelerometers in case of failure/problems. Thus, several orbit estimation runs will be carried out for each Swarm satellite. It has to be noted that the estimated time series of non-gravitational accelerations from the highly reduced-dynamic orbit solutions cover only the longer wavelengths or low frequencies of, for example, atmospheric drag perturbations. As such, they cannot replace the accelerometer observations for an important part of the frequency range.

(iv) Finally, a number of quality checks will be carried out. The correctness of the POD process is assessed by, for example, checking convergence and stability of the iterative estimation process (i.e. formal errors of, and correlations between, estimated parameters), the observation fit and overlap analysis between consecutive orbit solutions. Depending on the availability of Satellite Laser Ranging (SLR) observations, the reduced-dynamic orbit solution will be confronted with these observations allowing an additional assessment of its accuracy. A quality report will be provided in PDF format.
The POD implementation builds on heritage from the High-Level Processing Facility, which was developed for the first ESA explorer mission, namely the Gravity field and steady-state Ocean Circulation Explorer (GOCE) (Visser et al., 2006). This implementation is operational for GOCE (Bock et al., 2011), but was also successfully tested with real data from the MetOp GNSS Receiver for Atmospheric Sounding (GRAS) instrument (Montenbruck et al., 2008). The GPS receivers on board of the Swarm satellites rely significantly on GRAS instrument technology.

Precise orbit determination requires a very detailed and comprehensive modeling and parameter estimation (Montenbruck and Gill, 2000), but does not require extensive computer resources. For example, daily GPS-based orbit computations can be done typically within one hour of CPU on a $3 \mathrm{GHz}$ Pentium IV PC with $2 \mathrm{~Gb}$ memory. The orbit solutions will be provided in SP3 format (SP3c, 2008). The accelerometer calibration parameters and the time series of estimated non-gravitational accelerations will be provided as NASA CDF files (GSFC, 2012).

\subsection{Thermospheric Density and Winds}

The TDW chain collects the accelerometer measurements and auxiliary data (such as solar and geomagnetic activity), and the relevant information from the POD chain, such as accelerometer calibration parameters and the orbit solutions (Figs. 1 and 3). It makes use of density and wind models, such as NRLMSIS-00 and HWM07 as well (Hedin et al., 1988, 1996; Picone et al., 2002; Drob et al., 2008). 


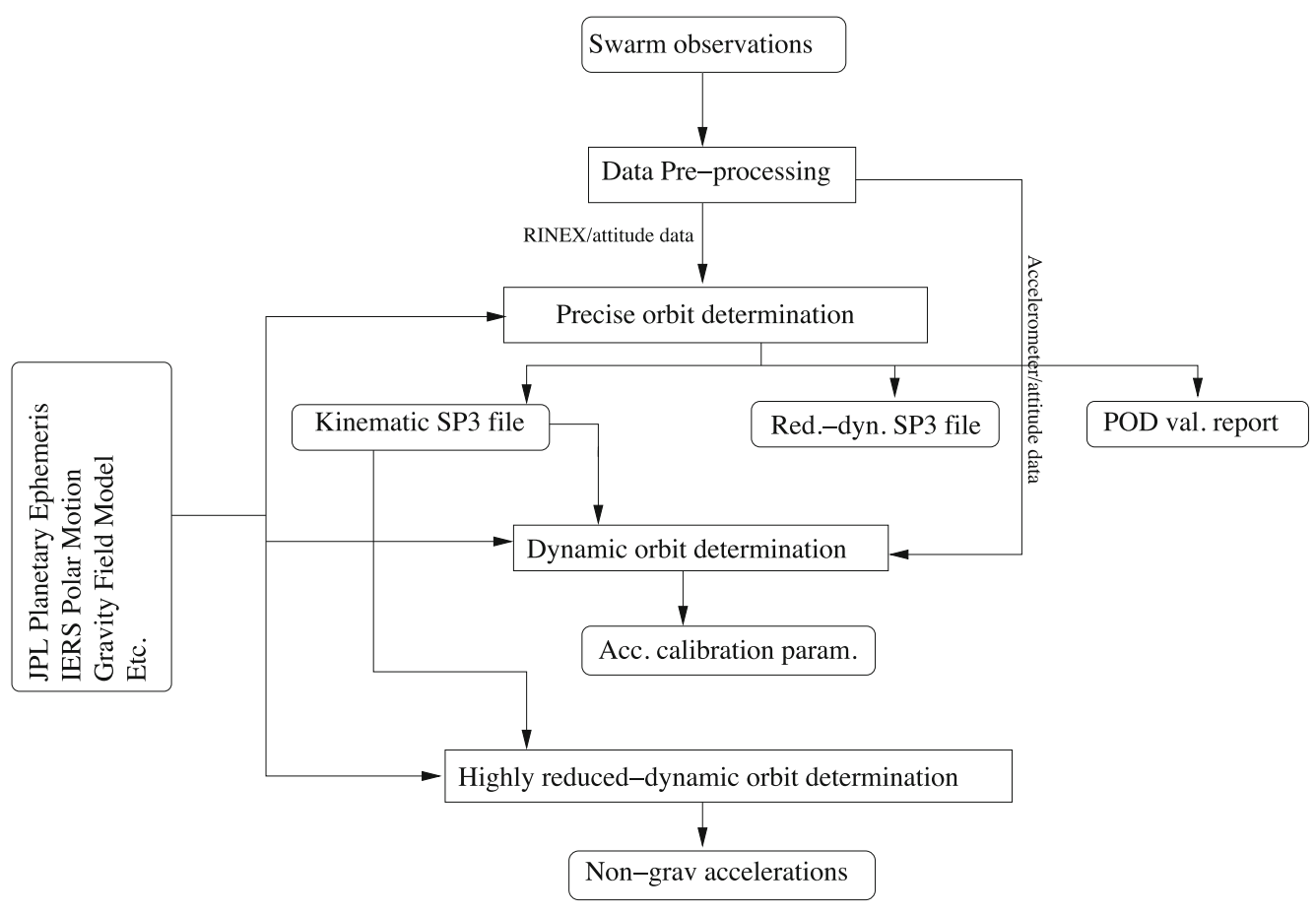

Fig. 2. TU-Delft POD chain.

The TDW chain produces calibrated and corrected time series of aerodynamic accelerations and neutral density and wind values.

Algorithms for density and wind retrieval have been defined, developed and implemented in the framework of the ESA study Air density models derived from multi-satellite drag observations (Doornbos et al., 2009). The density and wind data from the three satellites are processed independently, but inter-comparisons, especially for the satellite lower pair, will be used for quality assessment.

The following processing steps are identified:

(a) Accelerometer pre-processing: Application of PODbased calibration parameters to the accelerometer data, resulting in calibrated accelerations; Removal of time instances from the accelerometer data where maneuver thrusts have occurred, or where the accelerometer data are not able to represent the external non-gravitational forces on the satellite for other reasons;

(b) Radiation pressure removal: Modeling of solar radiation pressure, Earth albedo radiation pressure and Earth infrared radiation pressure, and subsequent removal of these accelerations from the accelerometer data, to arrive at accelerations due to aerodynamics only;

(c) Derivation of thermospheric density and winds from the aerodynamic accelerations; In this derivation, the $Y$ and $Z$ components of the accelerometer observations are calibrated using model-predicted values, where the model was calibrated for the $X$ direction using the POD-based calibration parameters (Doornbos et al., 2010);

(d) Quality assessment of density and winds: Comparisons with equivalent values obtained from empirical models (for instance NRLMSISE-00 and HWM07) and with past time series.

(e) Consolidation in the final Level 2 product output.

Accelerometer calibration parameters are estimated for all axes by means of POD (step a). However, for the derivation of thermospheric density and winds (step c) only the POD-based calibration parameters for the $X$ axis are always used and kept fixed. The POD-based values for the $Y$ and $Z$ axes are ignored. The calibrated $X$-axis accelerometer observations are used to determine the density. Having the density allows for the computation of the modeled acceleration in the $Y$ and $Z$ directions (also along the $X$ axis, but that would simply result in the original calibrated accelerometer observation). The modeled accelerations are simply the sum of the radiation pressure and aerodynamic force model output. The $Y$ and $Z$ axis accelerometer observations are then calibrated by estimating daily bias values which minimize the difference between observed and modeled observations (Doornbos et al., 2010).

The feasibility of the procedure for deriving thermospheric density and winds from accelerometer observations was assessed by a detailed simulation study reported in chapter 12 of Doornbos et al. (2009). This study revealed that variations in the $Y$-axis bias (predominantly in the cross-track direction) pose a major limitation in the observing system. Reducing or eliminating the bias error requires a stable and accurate acceleration reference. Fortunately, changes in bias mostly seem to occur relatively slowly on earlier accelerometers (CHAMP and GRACE), so that daily bias estimates can be sufficient. However, bias estimation in a POD process using GPS tracking over daily arcs does not seem to result in the desired accuracy (less than a few $\mathrm{nm} / \mathrm{s}^{2}$ ) for the $Y$-axis accelerations for CHAMP and GRACE. The rules of orbital dynamics dictate that the cross-track bias is much less well determined that the along- 


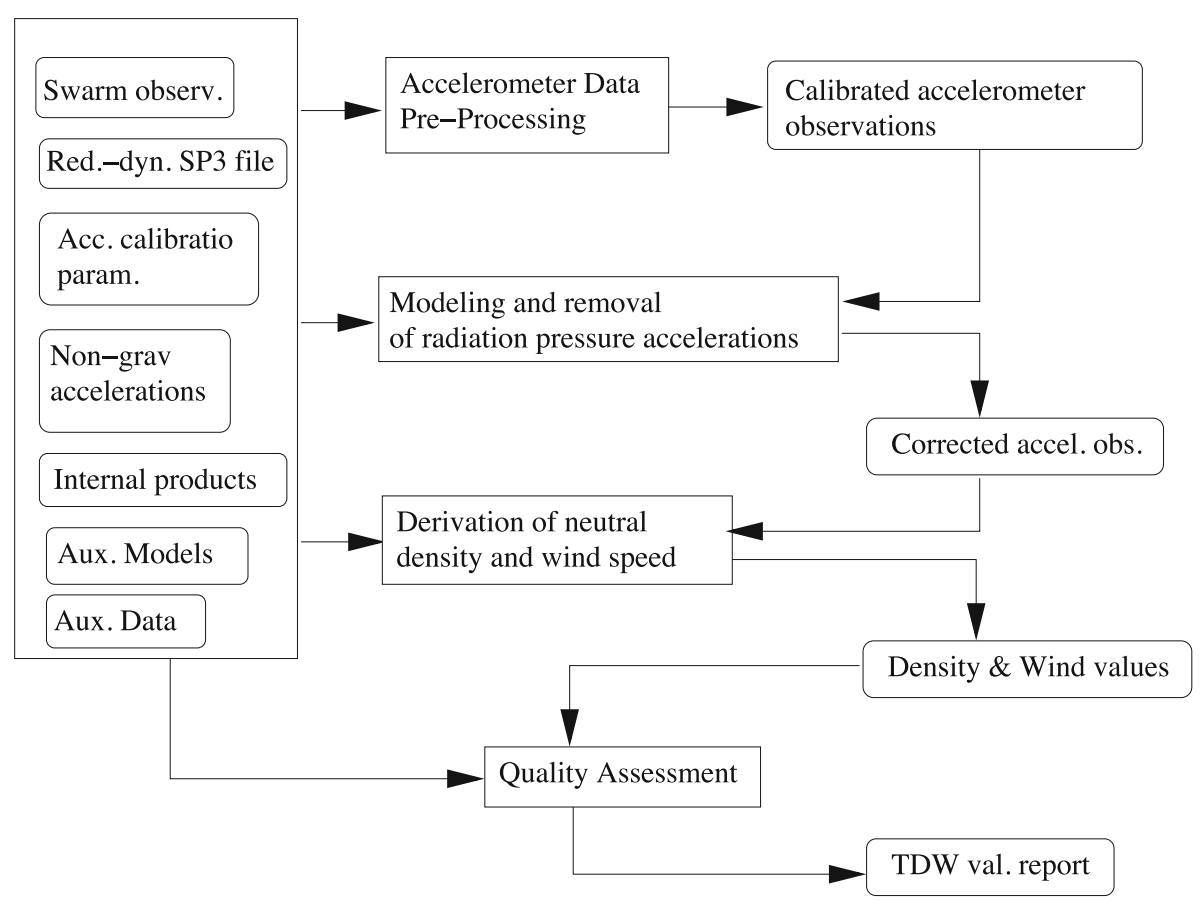

Fig. 3. TU-Delft TDW chain.

track bias (see also Subsection 4). Therefore, the $Y$-axis bias is instead determined by the procedure outlined in the previous paragraph.

It is important to note that model densities (e.g. as could be predicted using the NRLMSISE-00 model) are not used anywhere in the processing. Because the aerodynamic force depends on the atmospheric temperature and composition, and there are no independent measurements of these quantities made by Swarm, the model temperatures and composition are used instead (in this case coming from NRLMSIS$00)$. These have only a few percent at most effect on the aerodynamic force coefficients, and therefore on the resulting density measurements.

Because only one $Y$-axis accelerometer bias parameter is estimated per day, the wind model (i.e. HWM07) can not have any effect on variations observed within the day, or even within a single orbit revolution. The use of the model in the acceleration bias removal carries however the risk of affecting the mean wind per day. If the model were omitted, this would result in a zero mean wind, which is less desirable than a mean wind equivalent to the mean wind of the model. The usability of the accelerometer derived wind values to improve models such as HWM07 are of course limited by this. This does not mean however that the wind observations are useless. For Swarm, the wind retrieval might be enhanced by using for example only low latitude data. The resulting wind observations might then be more useful to study the high latitude wind variations. This is currently under investigation.

The wind error is determined by the magnitude of the acceleration bias and radiation pressure model errors with respect to the aerodynamic acceleration signal. Thus, at lower altitudes and at high solar activity, bias errors will become less of a problem. It is important to note that at the start of the Swarm mission, the satellites will be at relatively high altitudes, comparable to the GRACE altitude and higher. Therefore, accurate crosswind data will almost certainly not be obtainable early on in the Swarm mission. Also, the true performance of the Swarm accelerometers, especially in terms of bias stability, will have to be evaluated in orbit during the commissioning phase, before any further statements can be made about the Swarm crosswind data accuracy, and its dependency on the wind model.

The primary purpose of comparing the density and wind speeds derived from the accelerometer observations with those predicted with the HWM07 and NRLMSISE-00 models (step d) is to assess the consistency of the input data from the satellite (accelerations, attitude, mass) with the force models and assumptions used in the density and wind derivation algorithm. The HWM07 and NRLMSISE-00 models which are used have only a limited effect on the output of the algorithm. To a large extent, different model outputs are used in the algorithm (namely temperature, composition, in-track wind) than in the comparisons (namely density, crosswind). Therefore, it is fair to assume that the use of these models in the comparisons will allow to correctly identify possible problems in the data. The only exception is the use of HWM07 crosswinds in both the accelerometer $Y$-axis calibration and quality assessment, which has already been addressed above.

In addition, further quality assessments are done by comparing observations of the lower flying Swarm satellites with each other. Finally, the calibrated accelerometer observations can be compared with the time series of estimated non-gravitational accelerations from the POD chain.

A real independent validation might be possible by using independent contemporaneous ground-based thermospheric wind data. This is currently under investigation, but is not done in the framework of the Swarm L2PS.

Typically, computing and data storage requirements are 


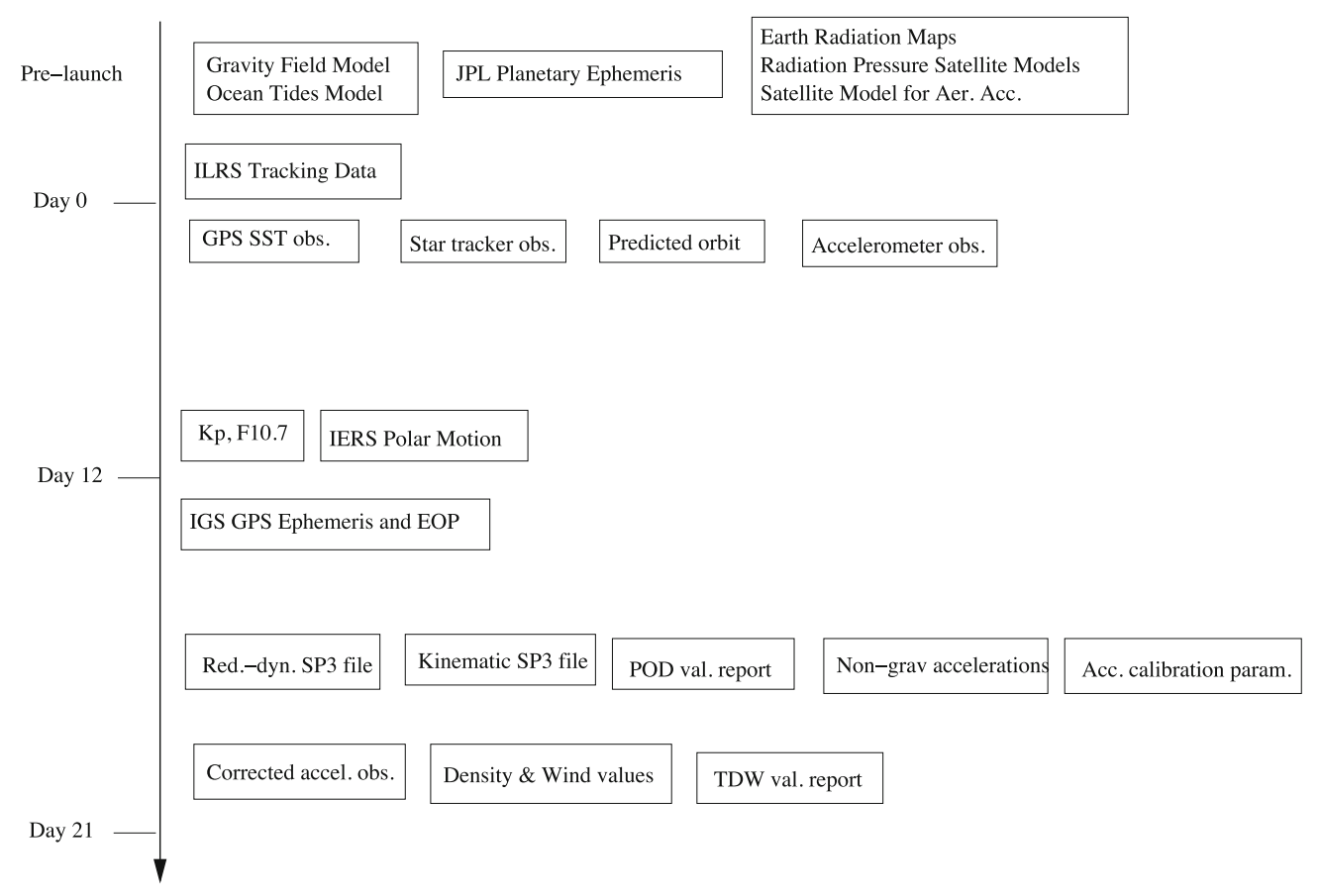

Fig. 4. Processing and product time line for the TU-Delft facility.

compatible with standard PCs with 2 GB memory and 500 GB of hard disk storage. The time series of corrected aerodynamic accelerations and the time series of mass density and wind values will be provided as NASA CDF files.

\subsection{Product time line}

The TU Delft facility provides a set of eight products (the used format for these products is indicated in parenthesis):

1. Reduced-dynamic orbit solution (SP3);

2. Kinematic orbit solution (SP3);

3. Orbit validation report $(\mathrm{PDF})$;

4. Estimated non-gravitational accelerations (NASA CDF);

5. Accelerometer calibration parameters (NASA CDF);

6. Corrected accelerometer observations (NASA CDF);

7. Mass density and wind values (NASA CDF);

8. Thermospheric density and wind validation report (PDF).

These products are produced on a daily basis and nominally cover a period from midnight to midnight. It is foreseen that these products will have a latency of three weeks (Fig. 4), allowing the use of precise supporting products such as those provided by the IGS. The data production can be automated to a large extent and it is possible to reduce this latency significantly down to less than a few days if e.g. use is made of rapid IGS products. This will reduce however the accuracy and reliability of the products, but might support applications such as the monitoring of space weather.

\section{Mass Density and Wind Retrieval Tests with CHAMP and GRACE Data}

The retrieval of mass density and wind by the TU Delft processing facility for Swarm has been tested by using real observations from the CHAMP and GRACE missions. The constellation of CHAMP and GRACE satellites resembles the Swarm constellation in that it consists of one pair of satellites flying in formation and one at a different altitude.
In the Swarm case, the satellites flying in formation are however at the lower altitude. Daily products were generated for two representative days: 7 and 8 November 2003 . The quality assessment of the GPS-based orbits produced by the POD chain indicates that the reduced-dynamic orbit solutions have a 3-dimensional precision of the order of $10 \mathrm{~cm}$ or better: the fit of independent SLR observations is in general of the order of a few $\mathrm{cm}$ and the consistency with the kinematic orbit solution is also at the $10 \mathrm{~cm}$ level 3-dimensionally (Table 2). The reduced-dynamic orbit solutions are more than sufficiently accurate for geolocating the accelerometer, density and wind products and as input for computations with density and wind models.

The thermospheric density and wind retrieval procedure requires the availability of precise values for the accelerometer bias and scale factor for the $X$ direction from the POD. As outlined in detail in Doornbos et al. (2010) and Doornbos (2011) and in Subsection 3.2, the calibration parameters for the $X$ axis are required to start an iterative procedure for obtaining the calibration parameters for the $Y$ and $Z$ axes together with mass density and wind values. The estimated scale factors from the POD match very well with those recommended or advertised for the $X$ axis, to within 0.01 for GRACE (Bettadpur, 2004) and 0.02 for CHAMP (provided in the CHAMP accelerometer data product). For the bias values, the agreement is within $10-15 \mathrm{~nm} / \mathrm{s}^{2}$ (Table 3). Please note that these advertised values are obtained by orbital analysis as well. The differences between the estimated and advertised values thus reflect the consistency level. It is possible that both types of values suffer from common errors. The values presented here are based on daily estimates, i.e. using only one day of observational data. After accumulating more data, the precision of the scale factor and bias estimates will improve and use can be made of the stacked matrices approach, where normal equa- 
Table 2. POD quality assessment: orbit differences between kinematic and reduced-dynamic orbit solutions and fit of SLR observations for the reduced-dynamic orbit solution.

\begin{tabular}{|c|c|c|c|c|c|c|}
\hline \multirow[t]{3}{*}{ Satellite } & \multirow[t]{3}{*}{ Date } & \multirow{2}{*}{\multicolumn{3}{|c|}{$\begin{array}{l}\text { RMS of orbit differences }(\mathrm{cm}) \\
\text { Reduced-dynamic vs. kinematic }\end{array}$}} & \multicolumn{2}{|c|}{ SLR residuals } \\
\hline & & & & & \multirow[t]{2}{*}{ Number } & \multirow[t]{2}{*}{$\mathrm{RMS}(\mathrm{cm})$} \\
\hline & & Radial & Along-track & Cross-track & & \\
\hline \multirow[t]{2}{*}{ GRACE-A } & 7 Nov. & 5.85 & 2.90 & 6.62 & 33 & 2.0 \\
\hline & 8 Nov. & 7.65 & 5.71 & 7.75 & 21 & 6.6 \\
\hline \multirow[t]{2}{*}{ GRACE-B } & 7 Nov. & 6.82 & 3.90 & 10.18 & 52 & 1.3 \\
\hline & 8 Nov. & 7.73 & 4.15 & 10.42 & 40 & 2.8 \\
\hline \multirow[t]{2}{*}{ CHAMP } & 7 Nov. & 5.27 & 4.53 & 5.32 & 142 & 2.6 \\
\hline & 8 Nov. & 6.60 & 4.82 & 5.77 & 114 & 2.0 \\
\hline
\end{tabular}

Table 3. Accelerometer calibration parameters: estimated by POD vs. advertised.

\begin{tabular}{|c|c|c|c|c|c|}
\hline \multirow[t]{2}{*}{ Satellite } & \multirow[t]{2}{*}{ Date } & \multicolumn{2}{|c|}{$\operatorname{Bias}\left(\mathrm{nm} / \mathrm{s}^{2}\right)$} & \multicolumn{2}{|c|}{ Scale factor } \\
\hline & & Advertised & Estimated & Advertised & Estimated \\
\hline \multicolumn{6}{|l|}{$X$ axis } \\
\hline \multirow[t]{2}{*}{ GRACE-A } & 7 Nov. & -1130 & -1127 & 0.960 & 0.962 \\
\hline & 8 Nov. & -1130 & -1122 & 0.960 & 0.958 \\
\hline \multirow[t]{2}{*}{ GRACE-B } & 7 Nov. & -553 & -557 & 0.960 & 0.944 \\
\hline & 8 Nov. & -553 & -561 & 0.960 & 0.951 \\
\hline \multirow[t]{2}{*}{ СНАMP } & 7 Nov. & -2961 & -2964 & 0.834 & 0.850 \\
\hline & 8 Nov. & -2961 & -2947 & 0.834 & 0.844 \\
\hline \multicolumn{6}{|l|}{$Y$ axis } \\
\hline \multirow[t]{2}{*}{ GRACE-A } & 7 Nov. & 28227 & 27940 & 0.980 & 0.979 \\
\hline & 8 Nov. & 28225 & 27964 & 0.980 & 0.980 \\
\hline \multirow[t]{2}{*}{ GRACE-B } & 7 Nov. & 8689 & 9175 & 0.970 & 0.972 \\
\hline & 8 Nov. & 8690 & 9173 & 0.970 & 0.971 \\
\hline \multirow[t]{2}{*}{ CHAMP } & 7 Nov. & 376 & 265 & 0.800 & 0.803 \\
\hline & 8 Nov. & 376 & 242 & 0.800 & 0.801 \\
\hline \multicolumn{6}{|l|}{$Z$ axis $^{1}$} \\
\hline \multirow[t]{2}{*}{ GRACE-A } & 7 Nov. & -500 & -372 & 0.940 & 0.940 \\
\hline & 8 Nov. & -500 & -365 & 0.940 & 0.940 \\
\hline \multirow[t]{2}{*}{ GRACE-B } & 7 Nov. & -775 & -630 & 0.920 & 0.920 \\
\hline & 8 Nov. & -775 & -665 & 0.920 & 0.920 \\
\hline CHAMP $^{2}$ & N/A & N/A & N/A & N/A & N/A \\
\hline
\end{tabular}

tions for the parameters estimated in the POD are combined to estimate, for example, one set of scale factors (which are in general stable for accelerometers) for a long time span but still daily updates of bias values (Helleputte and Visser, 2009).

The mean of the non-gravitational acceleration along the $X$ axis is about $-200 \mathrm{~nm} / \mathrm{s}^{2}$ for GRACE and $-600 \mathrm{~nm} / \mathrm{s}^{2}$ for CHAMP (Fig. 5). Thus, the above mentioned discrepancy between the estimated and advertised accelerometer bias values would then lead to an error level of about $5 \%$ and $2.5 \%$ for GRACE and CHAMP, respectively, in terms of the mean non-gravitational acceleration and the derived air drag values (Eq. (2)). This is much below the uncertainty level of existing drag models (Doornbos, 2011).

For the $Y$ axis, the consistency between estimated and advertised scale factor values is better than 0.01 , but the bias values have a discrepancy at the level of $100-500 \mathrm{~nm} / \mathrm{s}^{2}$ (Table 3). This is also reflected by Fig. 5 (middle): the mean between modeled and estimated accelerations is about 75 $\mathrm{nm} / \mathrm{s}^{2}$ for GRACE-A on 7 November 2003. The discrep- ancy for the associated bias value is $9175-8689=486$ $\mathrm{nm} / \mathrm{s}^{2}$. The advertised values thus appear to have a large uncertainty for the $Y$ axis as well ( $c f$. Helleputte and Visser, 2009). This uncertainty can be explained to a large extent by the POD estimation process. High correlations exist between the initial position and the accelerometer bias in the cross-track direction (predominantly aligned with the $Y$ axis). This is reflected by the formal error that can be obtained from the POD estimation process: for GRACE the formal error for the $Y$ axis accelerometer bias estimate is about two orders of magnitude larger than for the $X$ axis. However, as indicated before, for the density and wind retrieval, only the precise estimate for the $X$ axis is used from the POD (Doornbos, 2011). Despite of this, it is planned to tune and tailor the different POD processes for Swarm taking into account the actual performance of the several instruments considered as soon as a sufficiently large data set has been accumulated. Moreover, it is foreseen that Swarm will conduct a couple of maneuvers during which the $X, Y$ and $Z$ axes of the accelerometers might deviate from the 
Table 4. Calibrated accelerometer observations vs. those predicted by models or estimated by POD (nm/s $\mathrm{s}^{2}, \sigma$ is RMS-about-mean).

\begin{tabular}{|c|c|c|c|c|c|c|}
\hline \multirow[t]{2}{*}{ Satellite } & \multirow{2}{*}{$\begin{array}{l}\text { Date } \\
2003 \\
\end{array}$} & \multirow{2}{*}{$\begin{array}{c}\text { Obs. } \\
\text { signal } \sigma\end{array}$} & \multicolumn{2}{|c|}{ Obs. vs. estimated } & \multicolumn{2}{|c|}{ Obs. vs. modeled } \\
\hline & & & Mean & $\sigma$ & Mean & $\sigma$ \\
\hline \multicolumn{7}{|l|}{$X$ axis } \\
\hline \multirow[t]{2}{*}{ GRACE-A } & 7 Nov. & 50.9 & 0.1 & 18.9 & -33.2 & 21.9 \\
\hline & 8 Nov. & 40.4 & -0.5 & 19.6 & -35.2 & 22.9 \\
\hline \multirow[t]{2}{*}{ GRACE-B } & 7 Nov. & 48.3 & 0.2 & 19.1 & 36.4 & 21.4 \\
\hline & 8 Nov. & 39.1 & 0.6 & 19.6 & 37.4 & 22.1 \\
\hline \multirow[t]{2}{*}{ CHAMP } & 7 Nov. & 152.4 & -0.4 & 74.3 & 151.0 & 69.1 \\
\hline & 8 Nov. & 127.6 & 0.4 & 63.1 & 150.3 & 71.7 \\
\hline \multicolumn{7}{|l|}{$Y$ axis } \\
\hline \multirow[t]{2}{*}{ GRACE-A } & 7 Nov. & 23.8 & 0.8 & 13.5 & -71.4 & 2.4 \\
\hline & 8 Nov. & 21.8 & -2.2 & 16.3 & -79.4 & 2.2 \\
\hline \multirow[t]{2}{*}{ GRACE-B } & 7 Nov. & 23.9 & 0.6 & 14.9 & -115.9 & 2.9 \\
\hline & 8 Nov. & 22.0 & 9.2 & 16.1 & -113.7 & 2.1 \\
\hline \multirow[t]{2}{*}{ CHAMP } & 7 Nov. & 41.2 & 63.4 & 17.2 & 36.8 & 11.4 \\
\hline & 8 Nov. & 33.0 & 59.0 & 18.0 & 15.0 & 12.0 \\
\hline \multicolumn{7}{|l|}{$Z$ axis } \\
\hline \multirow[t]{2}{*}{ GRACE-A } & 7 Nov. & 12.5 & 7.5 & 12.8 & 146.3 & 4.1 \\
\hline & 8 Nov. & 12.4 & 13.6 & 12.5 & 153.5 & 4.0 \\
\hline \multirow[t]{2}{*}{ GRACE-B } & 7 Nov. & 14.4 & 6.3 & 14.5 & 166.3 & 3.9 \\
\hline & 8 Nov. & 13.9 & -19.1 & 14.0 & 130.8 & 3.7 \\
\hline CHAMP & N/A & N/A & N/A & N/A & N/A & N/A \\
\hline
\end{tabular}

nominally Earth-pointing orientation. During such occasions improved estimates for the accelerometer bias along the $Y$ and $Z$ axes might be obtained as well.

The non-gravitational acceleration signal is very small for the $Z$ axis, which means it can hardly be scaled by orbital analysis or POD. Therefore, for this direction only a bias is estimated and this is done for the GRACE satellites only. For CHAMP, the $Z$ axis accelerations were not used due to a failed electrode (see also Fig. 5). Finally, it has to be noted that the advertised values depend to a large extent on orbital analysis as well, conducted by the institutes that provide the supporting data. Thus the comparison between the advertised and estimated values cannot be considered as a completely independent validation.

As explained in Subsection 3.1, a highly-reduced dynamic POD is conducted using the best gravitational force models in order to estimate time series of non-gravitational accelerations. The current setup allows the estimation of piecewise linear accelerations with a 15 min time interval between the nodes. These accelerations are used for comparison and validation of the calibrated observed accelerations. Such a comparison is displayed in Fig. 5, which includes not only these estimated non-gravitational accelerations, but also those predicted by models and the calibrated observed accelerations. For the $X$ axis, the size of the variations of the calibrated observed accelerations matches well with that of the estimated accelerations. The variations of the modeled non-gravitational accelerations appear to have a higher amplitude, which is an indication that the selected aerodynamic model overestimates the neutral density. The latter will be addressed further below. For the $Y$ axis, it can be observed that the variations between modeled accelerations on the one hand and estimated and calibrated observed accelerations on the other hand match quite well, but that a significant mean offset is present. The latter reflects again
Table 5. Mean and RMS-about-mean $(\sigma)$ of the ratio of the density derived from the accelerometer observations and the one predicted by the NRLMSISE-00 model.

\begin{tabular}{cclc}
\hline Satellite & Date & \multicolumn{2}{l}{ Ratio $\rho$ obs./modeled } \\
& 2003 & Mean & $\sigma$ \\
\hline GRACE-A & 7 Nov. & 0.799 & 0.114 \\
& 8 Nov. & 0.750 & 0.111 \\
GRACE-B & 7 Nov. & 0.769 & 0.111 \\
& 8 Nov. & 0.727 & 0.115 \\
CHAMP & 7 Nov. & 0.732 & 0.081 \\
& 8 Nov. & 0.701 & 0.089 \\
\hline
\end{tabular}

the uncertainty of the biases estimated by POD for this direction. Moreover, for GRACE-A it can be observed that for the $Z$ axis the variations also match quite well for all time series, apart from the estimated ones for which it is known that they cannot be determined very well by POD (van den IJssel and Visser, 2004a, b).

The RMS-about-mean of differences between modeled and calibrated observed non-gravitational accelerations is much lower than the signal variation magnitude for all three axes (Table 4). For example, for GRACE-A these values are respectively equal to 21.9 and $50.9 \mathrm{~nm} / \mathrm{s}^{2}$ on 7 November 2003 for the $X$ axis. For the $Z$ axis, these values are respectively 4.1 and $12.5 \mathrm{~nm} / \mathrm{s}^{2}$. When comparing the estimated accelerations with the calibrated observed ones, comparable RMS-about-mean values are obtained for the $X$ axis, whereas for the $Y$ and $Z$ axis the consistency is much worse. For the $Y$ axis the RMS-about-mean value is still significantly below the signal variation magnitude, whereas this is no longer the case for the $Z$ axis.

The effect of altitude on the RMS-about-mean of the nongravitational acceleration signal can be observed in Table 4 as well. For the selected two days, the altitude of CHAMP is 

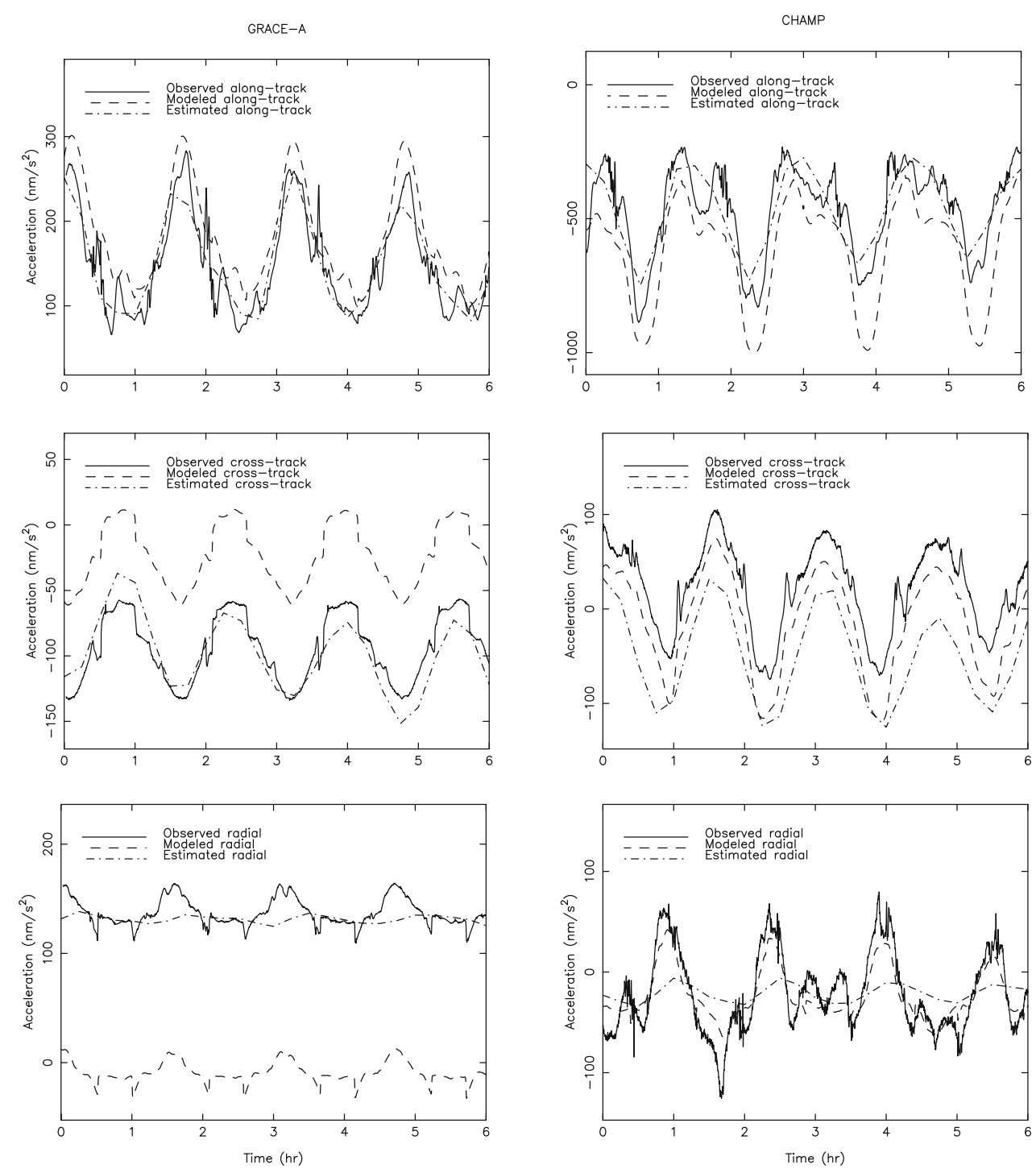

Fig. 5. Observed, estimated and modeled non-gravitational accelerations for the along-track (top), cross-track (middle) and radial (bottom) direction (first $6 \mathrm{hr}$ of 7 November 2003).

about $390 \mathrm{~km}$ compared to about $480 \mathrm{~km}$ for GRACE-A/B. This results in much higher variations of the accelerations, a factor of about 3 for the $X$ axis and 1.5 for the $Y$ axis. These higher variations lead to a more precise estimation of accelerometer scale factors (Helleputte and Visser, 2009). In addition, when deriving the aerodynamic accelerations from the total non-gravitational accelerations (Eq. (1)), correction errors are relatively smaller. For Swarm this means that more and more precise results are anticipated as the mission evolves, since the Swarm satellites will slowly decay to lower altitudes. Moreover, the results for the lower flying pair are anticipated to be more precise as well.

It has to be noted that the consistency between observed and modeled density values will improve when a scale factor for the density model would be estimated and taken into account, which would correct for the higher neutral density values observed for existing density models, which typically is of the order of $20-30 \%$ for the selected data period and model (Doornbos, 2011). Calibration of such density models is in fact one of the relevant objectives of retrieving mass density values from the accelerometer observations. Table 5 includes the values for the mean and RMS-aboutmean for the ratio of observed and modeled mass density at satellite level. The mean value is equal to about 0.72 for CHAMP, indicating a $30 \%$ overestimation, and 0.77 for GRACE-A/B, indicating a $20 \%$ overestimation of air density by the adopted model. The RMS-about-mean reflects hight-frequency density fluctuations that are not captured by the density model, but are observed by the accelerometers. For CHAMP and GRACE, this is at a level of about 8 and $11 \%$, respectively. For a higher altitude, a higher value is anticipated: existing density models become more uncertain with increasing altitude.

A few selected time series of retrieved (or observed) and modeled air density for CHAMP and GRACE-A are displayed in Fig. 6. The difference in scale can be observed quite well as well as a clear 1 cycle-per-orbital-revolution (cpr) signature, with is due to the small eccentricity of the CHAMP and GRACE orbits (0.001-0.003). The ellipsoidal shape of the Earth causes a 2 cpr modulation. 
Table 6. Observed and modeled Eastward crosswinds.

\begin{tabular}{|c|c|c|c|c|c|c|c|}
\hline \multirow[t]{2}{*}{ Satellite } & \multirow{2}{*}{$\begin{array}{l}\text { Date } \\
2003\end{array}$} & \multirow[t]{2}{*}{ Description } & \multicolumn{5}{|c|}{ Crosswind $(\mathrm{m} / \mathrm{s})$} \\
\hline & & & Min & $\operatorname{Max}$ & Mean & RMS & $\sigma$ \\
\hline \multirow[t]{4}{*}{ GRACE-A } & 7 Nov. & HWM07 & -236 & 207 & -15 & 70 & 69 \\
\hline & & Observed & -848 & 1133 & 80 & 213 & 198 \\
\hline & 8 Nov. & HWM07 & -244 & 274 & -13 & 72 & 71 \\
\hline & & Observed & -1061 & 1241 & 46 & 301 & 298 \\
\hline \multirow[t]{4}{*}{ GRACE-B } & 7 Nov. & HWM07 & -237 & 231 & -14 & 69 & 67 \\
\hline & & Observed & -796 & 1163 & 97 & 224 & 202 \\
\hline & 8 Nov. & HWM07 & -244 & 274 & -14 & 72 & 70 \\
\hline & & Observed & -973 & 1144 & 76 & 286 & 276 \\
\hline \multirow[t]{4}{*}{ CHAMP } & 7 Nov. & HWM07 & -181 & 184 & -3 & 55 & 55 \\
\hline & & Observed & -528 & 414 & 13 & 102 & 101 \\
\hline & 8 Nov. & HWM07 & -185 & 207 & -2 & 55 & 55 \\
\hline & & Observed & -909 & 441 & -23 & 159 & 157 \\
\hline
\end{tabular}
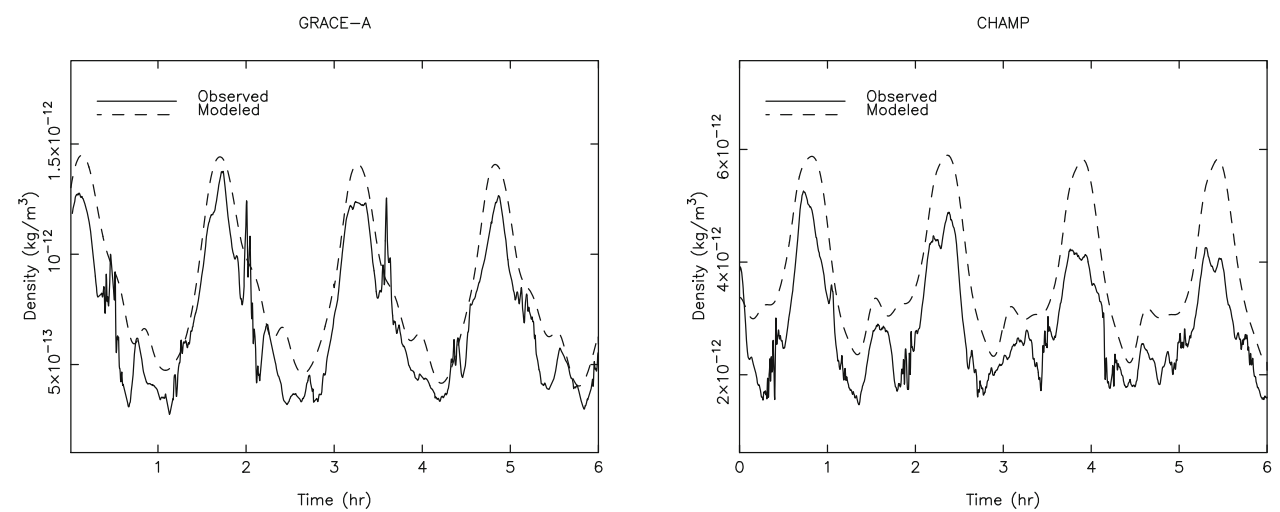

Fig. 6. Observed and modeled density (first 6 hr of 7 November 2003).
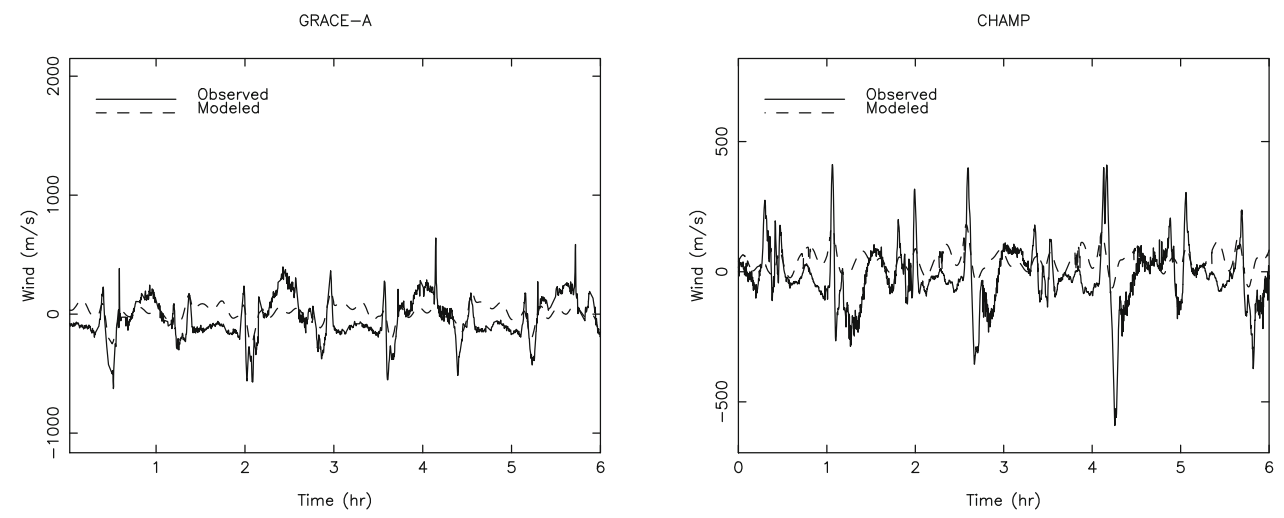

Fig. 7. Observed (or retrieved) and modeled crosswind speed in the Eastward direction (first 6 hr of 7 November 2003). Please note the difference in scale between the left and right plots.

The crosswinds are derived simultaneously with the neutral density values. Selected time series are displayed in Fig. 7 together with model predictions. The model predictions in general provide overly smooth time series and typically underestimate the magnitude of crosswinds in polar regions (Drob et al., 2008; Doornbos, 2011). The peak values in Fig. 7 are typically occurring when the satellites cross the auroral oval. The observed crosswinds display much larger excursions for the GRACE satellites than for CHAMP. The GRACE satellites fly at significantly higher altitudes leading to a less reliable wind retrieval. For CHAMP, significant wind retrieval results have been obtained (Lühr et al., 2007; Doornbos et al., 2010) for periods of high solar activity at relatively low altitudes. For Swarm, it will thus be challenging to provide meaningful wind products at the start of the mission, especially for the higher flying satellite. 


\section{Summary and Conclusions}

The instrumentation package on board of the Swarm satellites includes high-precision, dual-frequency GPS receivers, accelerometers and star trackers. This combination of instruments allows the very precise geolocation of Swarm observations. In addition, the accelerometer can be calibrated very precisely for the component in the flight direction, which is the dominant direction of the non-gravitational accelerations. This calibration is a prerequisite for deriving mass density and-if conditions are favorable — crosswinds at satellite altitudes.

The production of daily time series of mass density and crosswind values form part of the Swarm Level 2 Processing System (L2PS). A comprehensive processing facility has been developed, implemented at tested by the TU Delft. The associated methods and procedures have been tested by using real data from the CHAMP and GRACE missions. Just like the Swarm constellation, CHAMP and GRACE together consist of three satellites as well, be it that the tandem is flying at the higher altitude. Although the altitudes of CHAMP and GRACE are lower than those of the Swarm satellites at the start of the mission, the complete functionality of the TU Delft facility has been tested rigorously and realistically with these data.

It has been demonstrated that the selected methods, procedures and setups result in CHAMP and GRACE orbit solutions with a precision of the order of $10 \mathrm{~cm} \mathrm{3-}$ dimensionally. In addition, precise estimates of accelerometer calibration parameters are obtained by precise orbit determination for the flight axis. The consistency with advertised instrument parameter values is around $0.01-0.02$ for daily estimates of the scale factors and $10-15 \mathrm{~nm} / \mathrm{s}^{2}$ for the biases. It is anticipated that more precise values will be obtained as the amount of observations accumulates with time. For the cross-track direction, reliable estimates for the scale factor can be obtained by precise orbit determination, but the estimate for the bias value comes with a significant uncertainty. The latter can be explained by high correlations between estimated parameters. Especially, the simultaneous estimation of the bias and initial position in the $Y$ axis direction leads to this uncertainty. The tuning and optimization of the associated precise orbit determination process is work in progress and a topic for further research.

The accelerometer calibration parameters for the flight direction (or $X$ axis) are necessary input for the mass density and wind retrieval processing scheme. The CHAMP and GRACE results obtained with the method by Doornbos (2011) also indicate that air density seems to be overestimated by existing models by about $20 \%$ for the GRACE altitude $(\approx 480 \mathrm{~km})$ and $30 \%$ for the CHAMP altitude $(\approx 390$ $\mathrm{km})$. This result should, however, be handled with care, since it depends on the reliability of the aerodynamic coefficients $\left(\mathbf{C}_{a}\right.$, Eq. (2)) for which precise knowledge about the satellite is required and in conjunction its interaction with the environment. The Swarm constellation offers the possibility to test and develop the underlying theories for identical satellites at different altitudes and thus thermospheric conditions. The accelerometer observations especially provide information about density fluctuations at shorter spatial and temporal scales than current models can, which seems to be at an RMS level of $9-11 \%$ of the magnitude of air density.

The CHAMP and GRACE results indicate that realistic crosswinds can be derived, capturing especially variations in the polar regions, when the satellites are flying at sufficiently low altitudes in combination with relatively high magnitudes of mass density, i.e. at periods of increased solar activity. It is fair to anticipate that especially during the later stages of the Swarm mission and especially for the lower pair of satellites, observations become available that will allow to further develop and enhance wind retrieval methods and procedures.

Acknowledgments. The TU-Delft Swarm processing facility forms part of the Swarm Level 2 Processing System (L2PS), which is a joint development between the Technical University of Denmark (DTU), the Helmholtz German Research Centre for Geosciences (GFZ), the Institut de Physique du Globe de Paris (IPGP), the Eidgenössische Technische Hochschule Zürich (ETH), the British Geological Survey (BGS), and Delft University of Technology (TU Delft). The European Space Agency is acknowledged for providing crucial support to this development.

\section{References}

Bettadpur, S., Recommendation for a-priori Bias \& Scale Parameters for Level-1B ACC Data (Release 00), http://podaac-www.jpl.nasa.gov, GRACE TN-04-02, 2004.

Bock, H., A. Jäggi, U. Meyer, P. Visser, J. van den IJssel, T. V. Helleputte, M. Heinze, and U. Hugentobler, GPS derived orbits for the GOCE satellite, J. Geod., 85, 807-818, doi:10.1007/s00190-011-0484-9, 2011.

Bowman, B. R., F. A. Marcos, K. Moe, and M. M. Moe, Determination of drag coefficient values for CHAMP and GRACE satellites using orbit drag analyses, in Astrodynamics 2007, Advances in the Astronautical Sciences, Vol. 129, Univelt Inc., San Diego, CA, USA, pp. 147-166, AAS 07-259, 2008.

Bruinsma, S., D. Tamagnan, and R. Biancale, Atmospheric densities derived from CHAMP/STAR accelerometer observations, Planet. Space Sci., 52(4), 297-312, doi:10.1016/j.pss.2003.11.004, 2004.

Bruinsma, S., J. Forbes, R. Nerem, and X. Zhang, Thermosphere density response to the 20-21 November 2003 solar and geomagnetic storm from CHAMP and GRACE accelerometer data, J. Geophys. Res., 111, doi:10.1029/2005JA011284, A0603, 1-14, 2006.

Cook, G. E., Satellite drag coefficients, Planet. Space Sci., 13(10), 929_ 946, 1965.

Doornbos, E., Thermospheric Density and Wind Determination from Satellite Dynamics, Ph.D. thesis, Delft Univ. of Technol., Delft, ISBN 97890-9026051-8, 2011.

Doornbos, E., M. Förster, B. Fritsche, T. van Helleputte, J. van den IJssel, G. Koppenwallner, H. Lühr, D. Rees, and P. Visser, Air density models derived from multi-satellite drag observations-final report, Tech. Rep. ESTEC contract 21022/07/NL/HE, TU Delft, 2009.

Doornbos, E., J. van den IJssel, H. Lühr, M. Förster, and G. Koppenwallner, Neutral density and crosswind determination from arbitrarily oriented multiaxis accelerometers on satellites, Journal of Spacecraft and Rockets, 47(4), 580-589, doi:10.2514/1.48114, 2010.

Dow, J., R. Neilan, and G. Gendt, The International GPS Service (IGS): Celebrating the 10th Anniversary and Looking to the Next Decade, $A d v$. Space Res., 36(3), 320-326, 2005.

Drob, D., J. Emmert, G. Crowley, J. Picone, G. Shepherd, W. Skinner, P. Hays, R. Niciejewski, M. Larsen, C. She, J. Meriwether, G. Hernandez, M. Jarvis, D. Sipler, C. Tepley, M. O’Brien, J. Bowman, Q. Wu, Y. Murayama, S. Kawamura, I. Reid, and R. Vincent, An empirical model of the earth's horizontal wind fields: HWM07, J. Geophys. Res., 113, A12304, doi:10.1029/2008JA013668, 2008.

ESA, Swarm-The Earth's Magnetic Field and Environment Explorers, Reports for Mission Selection, The Six Candidate Earth Explorer Missions, SP-1279(6), European Space Agency, 2004.

Forbes, J. M., G. Lu, S. Bruinsma, S. Nerem, and X. Zhang, Thermosphere density variations due to the 15-24 april 2002 solar events from CHAMP/STAR accelerometer measurements, J. Geophys. Res., 110, A12S27, doi:10.1029/2004JA010856, 2005. 
Friis-Christensen, E., H. Lühr, D. Knudsen, and R. Haagmans, SwarmAn Earth Observation Mission investigating Geospace, Adv. Space Res., 41, 210-216, doi:10.1016/j.asr.2006.10.008, 2008.

Fritsche, B., M. Ivanov, A. Kashkovsky, G. Koppenwallner, A. Kudryavtsev, U. Voskoboinikov, and G. Zhukova, Radiation Pressure Forces on Complex Spacecraft, Tech. Rep. Final Report, Hyperschall Technologie Göttingen, TR HTG 98-8, Katlenburg-Linday, Germany, HTG, 1998.

Gerlach, C. and P. Visser, Swarm and gravity: possibilities and expectations for gravity field recovery, in First International Science Meeting, SWARM, 3-5 May 2006, Nantes, France, 7 pp., ESA WPP-261, July 2006, 2006.

GSFC, Common Data Format, Tech. Rep. http://cdf.gsfc.nasa.gov/ last accessed, 7 September 2012, NASA Goddard Space Flight Center, Space Physics Data Facility, 2012.

Hedin, A. E. et al., Empirical global model of upper thermosphere winds based on atmosphere and dynamics explorer satellite data, J. Geophys. Res., 93, 9959-9978, 1988.

Hedin, A., E. Fleming, A. Manson, F. Schmidlin, S. Avery, R. Clark, S. Franke, G. Fraser, T. Tsuda, F. Vial, and R. Vincent, Empirical wind model for the upper, middle and lower atmosphere, J. Atmos. Terr. Phys., 58, 1421-1447, 1996.

Helleputte, T. V. and P. Visser, CHAMP and GRACE accelerometer calibration by GPS based orbit determination, Adv. Space Res., 43(12), 1890-1896, doi:10.1016/j.asr.2009.02.017, 2009.

Liu, H. and H. Lühr, Strong disturbances of the upper thermospheric density due to magnetic storms: CHAMP observations, J. Geophys. Res., 110, A09829, doi:10.1029/2004JA010908, 2005.

Liu, H., H. Lühr, V. Henize, and W. Köhler, Global distribution of the thermospheric total mass density derived from CHAMP, J. Geophys. Res., 110, A04301, doi:10.1029/2004JA010741, 2005.

Liu, H., H. Lühr, S. Watanabe, W. Köhler, V. Henize, and P. Visser, Zonal winds in the equatorial upper thermosphere: Decomposing the solar flux, geomagnetic activity, and seasonal dependencies, J. Geophys. Res., 111, A07307, doi:10.1029/2005JA011415, 2006.

Lühr, H., M. Rother, W. Kahler, P. Ritter, and L. Grunwaldt, Thermospheric up-welling in the cusp region, evidence from CHAMP observations, Geophys. Res. Lett., 31, L06805, doi:10.1029/2003GL019314, 2004.

Lühr, H., S. Rentz, P. Ritter, H. Liu, and K. Häusler, Average thermospheric wind pattern over the polar regions, as observed by CHAMP, Ann. Geophys., 25(5), 1093-1101, 2007.

Marcos, F. and J. Forbes, Thermospheric winds from the satellite electrostatic triaxial accelerometer system, J. Geophys. Res., 90, 6543-6552, 1985.

Marcos, F., H. Garrett, K. Champion, and J. Forbes, Density variations in the lower thermosphere from analysis of the AE-C accelerometer measurements, Planet. Space Sci., 25(5), 499-507, 1977.

McCarthy, D. and G. Petit, IERS Conventions (2003), IERS Technical Note 32, 127 pp., Frankfurt am Main: Verlag des Bundesamts für Kartographie und Geodäsie, paperback, ISBN 3-89888-884-3, 2004.

Moe, K. and M. M. Moe, Progress in calculating satellite drag coefficients from orbital measurements, in AIAA Advanced Measurement and Ground Testing Technology Conference, 19th, New Orleans, LA, June 17-20, 1996, A9636660, AIAA Paper 96-2233, 1996.

Moe, K. and M. M. Moe, Gas-surface interactions and satellite drag coefficients, Planet. Space Sci., 53(8), 793-801, 2005.

Moe, K. and M. M. Moe, Method for deriving densities and in-track winds, in AIAA/AAS Astrodynamics Specialist Conference and Exhibit, 21-24
August 2006, Keystone, Colorado, 2006.

Moe, K., M. Moe, and S. Wallace, Improved satellite drag coefficient calculations from orbital measurements of energy accomodation, Journal of Spacecraft and Rockets, 35(3), 266-272, 1998.

Montenbruck, O. and E. Gill, Satellite Orbits-Models Methods Applications, Springer, ISBN 3-540-67280-X, 2000.

Montenbruck, O., T. V. Helleputte, R. Kroes, and E. Gill, Reduced dynamic orbit determination using GPS code and phase observations, Aerosp. Science \& Tech., 9(3), 261-271, 2005.

Montenbruck, O., Y. Andres, H. Bock, T. V. Helleputte, J. van den IJssel, M. Loiselet, C. Marquardt, P. Silvestrin, P. Visser, and Y. Yoon, Tracking and Navigation Performance of the GRAS Instrument on MetOp-A, GPS Sol., 12(4), 289-299, doi:10.1007/s10291-008-0091-2, 2008.

Olsen, N., P. Alken, C. Beggan et al., SCARF-The Swarm Satellite Constellation Application and Research Facility, American Geophysical Union, Fall Meeting 2011, Abstract, 2011.

Pavlis, D., S. Poulouse, and J. McCarthy, GEODYN Operations Manual, Contractor report, SGT Inc., Greenbelt, MD, 2006.

Pearlman, M., J. Degnan, and J. Bosworth, The international laser ranging service, Adv. Space Res., 30(2), 135-143, doi:10.1016/S02731177(02)00277-6, 2002.

Picone, J., A. Hedin, D. Drob, and A. Aikin, NRLMSISE-00 empirical model of the atmosphere: Statistical comparisons and scientific issues, J. Geophys. Res., 107(A12), doi:10.1029/2002JA009430, 2002.

Reigber, C., P. Schwintzer, and H. Lühr, The CHAMP geopotential mission, in Bollettino di Geofisica Teoretica ed Applicata, Vol. 40, No. 3-4, Sep.-Dec. 1999, Proceedings of the 2nd Joint Meeting of the International Gravity and the International Geoid Commission, Trieste 7-12 Sept. 1998, ISSN 0006-6729, pp. 285-289, 1999.

Sentman, L., Free Molecule Flow Theory and Its Application to the Determination of Aerodynamic Forces, Tech. rep., Lockheed Missiles and Space TR LMSC-448514, Sunnyvale, CA, 1961.

SP3c, The Extended Standard Product 3 Orbit Format (SP3-c), ftp://igscb.jpl.nasa.gov/igscb/data/format/sp3c.txt, last accessed, 30 June 2008, 2008.

Tapley, B. and C. Reigber, GRACE: a satellite-to-satellite tracking geopotential mapping mission, in Bollettino di Geofisica Teoretica ed Applicata, Vol. 40, No. 3-4, Sep.-Dec. 1999, Proceedings of the 2nd Joint Meeting of the International Gravity and the International Geoid Commission, Trieste 7-12 Sept. 1998, ISSN 0006-6729, p. 291, 1999.

van den IJssel, J. and P. Visser, Determinations of non-conservative accelerations from orbit analysis, in Earth Observation with CHAMP, Results from Three Years in Orbit, pp. 95-100, 2004a.

van den IJssel, J. and P. Visser, SWARM End-to-end Simulator: CCN 2SoW ref. EOP-SM/1000/Is.:1-2, 62 pages, Final report, DEOS, 2004b.

Visser, P. and J. van den IJssel, Verification of CHAMP accelerometer observations, Adv. Space Res., 31(8), 1905-1910, 2003.

Visser, P., J. IJssel, T. V. Helleputte, H. Bock, A. Jaeggi, G. Beutler, U. Hugentobler, and D. Svehla, Rapid and precise orbit determination for the GOCE satellite, in $3^{\text {rd }}$ GOCE User Workshop, 6-8 November 2006, Frascati, Italy, pp. 235-239, ESA SP-627, 2006.

Zaglauer, A., Swarm satellites status, in ESA's Second Swarm International Science Meeting, 24-26 June 2009, GFZ, Potsdam, Germany, pp. 1-33, ESA WPP-303, S1-01, 2009.

P. Visser (e-mail: P.N.A.M.Visser@tudelft.nl), E. Doornbos, J. van den IJssel, and J. T. da Encarnação 